\title{
The Past Four Years Research Work of the Adult Attention-Deficit/Hyperactivity Disorder Special Interest Group in the Korean Academy of Child and Adolescent Psychiatry
}

\author{
Young Sik Lee \\ Guest Editor, Chairman of Adult ADHD Special Interesting Group \\ Department of Psychiatry, Chung-Ang University Hospital, Seoul, Korea
}

According to the Diagnostic and Statistical Manual of Mental Disorders, fifth edition [1], attention-deficit/hyperactivity disorder (ADHD) is subcategorized as a neurodevelopmental disorder. Actual long-term follow-up studies show that the disorder persists into adulthood in $40-60 \%$ of children with $\mathrm{ADHD}$. The mean worldwide prevalence of $\mathrm{ADHD}$ is between 5.3\% [2] and 7.1\% [3] in children and adolescents under 18 years old and $4.4 \%$ in adults [4]. The problems of ADHD in adults are different from those in children. In the transition from childhood to adulthood, the diminishing symptoms of hyperactivity may transform into restlessness, whereas the persisting symptoms of inattention and impulsivity may manifest as difficulties with academic performance, occupational tasks, financial management, interpersonal problems, psychiatric comorbidities (anxiety, depression, and substance abuse), and poor health outcomes, including a higher risk of accidents.

Due to the public advertisement of adult ADHD, the diagnosis of ADHD in adults has become a hot issue in the last 10 years in Korea. Many people in their 20s and 30s, mainly jobseeking university students or white collar employees, voluntarily visited general psychiatrists for the first time in their lives for the confirmation of an ADHD diagnosis and to receive management to achieve better executive function. Furthermore, the population visiting psychiatric clinics increased due to a policy where the national health insurance started to cover ADHD in adults from September 2016. However, the treatment rate of ADHD in adults is still much lower than its prevalence in Korea, similar to findings from other countries $[4,5]$.

To decrease the underestimation or misdiagnosis of ADHD in adults, many Korean psychiatrists, mainly child psychiatrists, have translated international adult ADHD self-report-

This is an Open Access article distributed under the terms of the Creative Commons Attribution Non-Commercial License (https://creativecommons.org/licenses/by-nc/4.0) which permits unrestricted non-commercial use, distribution, and reproduction in any medium, provided the original work is properly cited. ing scales, and developed new Korean adult ADHD self-reporting scales based on other scales and computerized diagnostic attention checking programs since 2010. The World Health Organization's (WHO's) Adult ADHD Self-Report Scale (ASRS) v1.1 Symptom Checklist [6] was translated into Korean and showed good reliability and validity [7]. Due to this study, the results of the ASRS Korean version have been used as evidence supportive of adult ADHD diagnosis and is reported to the national health insurance service. Subsequently in 2018 [8], this research group showed that the 18-question ASRS outperformed the six-question ASRS Screener, but the weighted screener was still also a valid and useful screening instrument, both in epidemiological surveys and clinical settings.

Meanwhile, to overcome copyright issues and in consideration of the cultural aspects and linguistic differences, the Korean Academy of Child and Adolescent Psychiatry (KACAP) organized a taskforce and developed the Korean Adult ADHD Rating Scale (K-AARS) [9] by referencing the Conners' AARS (66 items), Brown Attention-Deficit Disorder Rating Scale for Adults (40 items), Wender Utah Rating Scale (61 items), ASRS (18 items), and Current Symptoms Scale (18 items). The K-AARS has 73 questions and consists of six clinical subscales (inattention, hyperactivity, impulsivity, antisocial personality disorder/ conduct disorder/oppositional defiant disorder, dysregulation, and disorganization), one impairment subscale, and one driving attitude subscale. The results of the K-AARS scores also provided evidence of an adult ADHD diagnosis and began to be reported to the national health insurance service. In 2019, the Adult ADHD Special Interest Group (AASIG) reported that the discriminative power of K-AARS for the diagnosis of adult ADHD was excellent [10].

The AASIG, a subgroup of the KACAP, started performing multicenter research in March 2016. Eight universities and one private clinic in Seoul were involved. The first research goal was to develop a structured interview instrument for more 
accurate adult ADHD diagnosis. Diagnostisch interview voor ADHD bij volwassenen-5 (DIVA-5) [11], K-AARS, WHOASRS, and mini-international neuropsychiatric interview [12] for detecting comorbid disorders, and a neurocognitive test including intelligence quotient testing and the Computerized Korean Comprehensive Attention Test (CAT) were applied to adult patients suspected of ADHD. The CAT study [13] presented standardized data on the different kinds of attention and working memory in children, adolescents, and adults in Korea.

Studies focusing on the reliability and validity of DIVA-5 in Korean adult $\mathrm{ADHD}$, clinical use of neurocognitive tests in adult $\mathrm{ADHD}$, and comorbidities of adult ADHD will be published in the near future. The principal investigators of these three papers are all key members of AASIG.

Another research goal of AASIG from March 2018 was to develop Korean practice parameters for adult ADHD. We analyzed questionnaires regarding the diagnosis and treatment process of adult ADHD completed by general psychiatrists and child and adolescent psychiatrists, and developed practice parameters for Koreans by reviewing the American, Canadian, and European practice parameters. In the previous volume of this journal, the results of this questionnaire survey are published [14], and show that identification of the initial presenting symptom with correct diagnosis and the optimal duration of pharmacotherapy differed between general psychiatrists and child and adolescent psychiatrists, whereas concepts in the diagnosis and treatment of ADHD in adults were similar for both groups. This suggested that continuing medical education programs for psychiatrists treating adults with ADHD are needed. Moreover, the paper, "Development of the Korean practice parameter for adult attention-deficit/hyperactivity disorder," is published in this journal [15].

In this editorial, the author briefly summarizes the past ten years of the development of Korean adult ADHD diagnostic work and introduces the past four years of research performed by the AASIG. We welcome any communication about co-research work or academic meetings from you.

\section{REFERENCES}

1) American Psychiatric Association. Diagnostic and Statistical
Manual of Mental Disorders, 5th edition: DSM-5. Washington DC: American Psychiatric Publishing;2013.

2) Polanczyk G, De Lima MS, Horta BL, Biederman J, Rohde LA. The worldwide prevalence of ADHD: a systematic review and metaregression analysis. Am J Psychiatry 2007;164:942-948.

3) Willcutt EG. The prevalence of DSM-IV attention-deficit/hyperactivity disorder: a meta-analytic review. Neurotherapeutics 2012; 9:490-499.

4) Kessler RC, Adler L, Barkley R, Biederman J, Conners CK, Demler $\mathrm{O}$, et al. The prevalence and correlates of adult ADHD in the United States: results from the National Comorbidity Survey Replication. Am J Psychiatry 2006;163:716-723.

5) Clarke S, Heussler H, Kohn MR. Attention deficit disorder: not just for children. Intern Med J 2005;35:721-725.

6) Kessler RC, Adler L, Ames M, Demler O, Faraone S, Hiripi E, et al. The World Health Organization Adult ADHD Self-Report Scale (ASRS): a short screening scale for use in the general population. Psychol Med 2005;35:245-256.

7) Kim JH, Lee EH, Joung YS. The WHO adult ADHD self-report scale: reliability and validity of the Korean version. Psychiatry Investig 2013;10:41-46.

8) Heo S, Kim JH, Joung YS, Lee WI, Kim JJ, Sohn SH, et al. Clinical utility of the Korean version of the WHO adult attention-deficit/ hyperactivity disorder self-report scale screener. Psychiatry Investig 2018;15:325-329.

9) Kang T, Kim JW, Bahn GH, Song SH, Kim J, Kim JH, et al. Development of Korean adult ADHD rating scale. J Korean Acad Child Adolesc Psychiatry 2015;26:295-310.

10) Hong M, Lee YS, Kim B, Joung YS, Yoo HK, Kim EJ, et al. Clinical utility and cut-off scores of the Korean adult attention-deficit/hyperactivity disorder rating scale. J Korean Acad Child Adolesc Psychiatry 2019;30:116-120.

11) DIVA Foundation. Diagnostic interview for ADHD in adults (DIVA). [cited 2019 Jun 17]. Available from URL: http://www.divacenter. eu/DIVA. aspx?id $=529 \& c c=K R$.

12) Yoo SW, Kim YS, Noh JS, Oh KS, Kim CH, NamKoong K, et al. Validity of Korean version of the mini-international neuropsychiatric interview. Anxiety and Mood 2006;2:50-55.

13) Huh HN, Kang SH, Hwang SY, Yoo HK. Developmental trajectories of attention in normal Korean population. J Korean Acad Child Adolesc Psychiatry 2019;30:66-73.

14) Hong M, Lee SY, Lee YS, Kim B, Joung YS, Yoo HK, et al. Comparison of attention-deficit/hyperactivity disorder practice in adults according to a training background in child psychiatry. J Korean Acad Child Adolesc Psychiatry 2019;30:121-126.

15) Bahn GH, Lee YS, Yoo HK, Kim EJ, Park S, Han DH, et al. Development of the Korean practice parameter for adult attention-deficit/hyperactivity disorder. J Korean Acad Child Adolesc Psychiatry 2020;31:5-25. 